\title{
Protocol: Chromatin immunoprecipitation (ChIP) methodology to investigate histone modifications in two model diatom species
}

\author{
Xin Lin, Leïla Tirichine* and Chris Bowler
}

\begin{abstract}
In this report we describe a chromatin immunoprecipitation (ChIP) protocol for two fully sequenced model diatom species Phaeodactylum tricornutum and Thalassiosira pseudonana. This protocol allows the extraction of satisfactory amounts of chromatin and gives reproducible results. We coupled the ChIP assay with real time quantitative PCR. Our results reveal that the two major histone marks H3K4me2 and H3K9me2 exist in P. tricornutum and T. pseudonana. As in other eukaryotes, H3K4me2 marks active genes whereas H3K9me2 marks transcriptionally inactive transposable elements. Unexpectedly however, T. pseudonana housekeeping genes also show a relative enrichment of H3K9me2. We also discuss optimization of the procedure, including growth conditions, cross linking and sonication. Validation of the protocol provides a set of genes and transposable elements that can be used as controls for studies using ChIP in each diatom species. This protocol can be easily adapted to other diatoms and eukaryotic phytoplankton species for genetic and biochemical studies.
\end{abstract}

Keywords: Phaeodactylum tricornutum, Thalassiosira pseudonana, Histone modifications, Chromatin immunoprecipitation, Epigenomics

\section{Background}

Diatoms are a group of eukaryotic phytoplankton with a wide distribution and a large diversity in marine and fresh water ecosystems. It is estimated that there are between 10,000 and 100,000 extant diatom species [1]. Diatoms play essential roles in global biogeochemical cycles because they are believed to be responsible for $20 \%$ of global carbon fixation and $40 \%$ of marine primary productivity [2]. Diatoms capture $\mathrm{CO}_{2}$ through photosynthesis and act as a critical buffer against global warming by sequestering organic carbon in the ocean interior. They can live under different conditions in all oceans from the poles to the tropics, and are often the first group of phytoplankton to benefit from sporadic nutrient upwelling events, indicating their intrinsic adaptability to changing environments.

Completed whole genome sequences from three species, the centric diatom Thalassiosira pseudonana,

\footnotetext{
*Correspondence: tirichin@biologie.ens.fr; cbowler@biologie.ens.fr Ecole Normale Supérieure, Institut de Biologie de l'ENS, IBENS, Inserm, U1024, CNRS, UMR 8197, Génomique, Environnementale et Evolutive Section 3 CNRS UMR8197, 46 rue d'Ulm, Paris 75005, France
}

and the pennate diatoms Phaeodactylum tricornutum and Fragilariopsis cylindrus are now available [3,4], (http://genome.jgi-psf.org/Fracy1/Fracy1.home.html).

Additional pennate species, the toxic Pseudo-nitzschia multiseries, Fistulifera sp. and Seminavis variabilis are also being sequenced and will provide an additional source for comparative genomics. T. pseudonana is widely distributed in marine environments and is of significant ecological importance. P. tricornutum on the other hand is considered to be of little ecological relevance but is the model system for pennate diatoms because of a long history of physiological experiments and the availability of a wide range of tools for reverse genetics $[5,6]$. Furthermore, a digital gene expression database (http://www.diatomics.biologie.ens.fr/EST3/index.php) is available for both species.

The whole genome sequences have revealed a wealth of information about diatom genes. It was shown for example that diatoms have acquired genes both from their endosymbiotic ancestors and by horizontal gene transfer from prokaryotes. But while DNA is the substrate for mutations upon which natural selection can act, DNA sequence in 
itself may not explain adequately their ability to adapt to changing environments, and more flexible mechanisms based on epigenetic processes could provide additional control. These changes include DNA methylation and histone tail post-translational modifications that alter chromatin structure. Study of diatom epigenomes can therefore provide a more in depth look at the regulatory mechanisms underlying their natural phenotypic adaptability to environmental changes.

Several tools for studying chromatin have been developed. Among them, chromatin immuno-precipitation (ChIP) has become a powerful tool to detect in vivo interactions between a DNA-associated protein and genomic DNA. ChIP combined with microarray or massively parallel sequencing is used to study gene regulatory networks active during development and/or in response to the environment. ChIP is also a valuable tool for mapping genome wide epigenetic modifications such as histone marks, and has been used to characterize several eukaryotic genomes $[7,8]$. However, no ChIP protocol has been reported for marine phytoplankton. T. pseudonana and P. tricornutum were therefore chosen to set up a ChIP protocol in diatoms using two histone marks known to characterize active and repressive chromatin states in other organisms.

The principle of a ChIP procedure includes: (1) Cross linking of DNA and protein with formaldehyde to covalently combine DNA and attached proteins in vivo, (2) Fragmentation of the fixed chromatin to an average size of $500 \mathrm{bp}$ ranging from 200 to $1000 \mathrm{bp}$, (3) Chromatin extraction by a succession of extraction buffers, (4) Immunoprecipitation with specific antibodies, (5) Purification of immune complexes after immunoprecipitation and reverse crosslinking, and (6) Analysis of bound DNA by PCR which involves comparison of the intensity of PCR signals from the precipitated template with positive and negative controls. Standard PCR on immunoprecipitated DNA from a specific genomic region provides a direct assessment of protein association with that region, whereas quantitative PCR can assess not only whether a protein binds to that region, but also further compare the relative abundance at different genomic regions.

The protocol described in this work was optimized for each of the steps described above. It is an adaptation of ChIP protocols used for yeast and Arabidopsis $[9,10]$. It is therefore not new in its principles but takes into consideration features inherent to diatoms such as their siliceous frustule, the cell wall and the chloroplast.

\section{Materials and methods Reagents:}

Formaldehyde 36.5\% (Fluka cat. No. 200018)

Glycine (Sigma cat. No. 2412)

Sucrose (Sigma cat. No. S-0389)
EDTA (Sigma cat. No. E-4884)

2-MERCAPTOETHANOL (Sigma cat. No. 125 k0165)

SDS (EUROMEDEX cat. No. EU660)

Triton X 100 (Amnersham bioscience)

Magnesium chloride (Sigma cat. No. 7786-30-3)

Sodium chloride (Sigma cat. No. 7647-14-5)

Sodium Acetate (Sigma cat. No. 127-09-3)

Lithium chloride (Sigma cat. No. 7447-41-8)

Sodium deoxycholate (Sigma cat. No. D-6750)

IGEPAL CA-630 (Sigma cat. No. 043 K0654)

$\mathrm{NaHCO}_{3}$ (Prolabo cat. No. 2 778.293)

Complete protease cocktail Inhibitor (Roche cat. No.

11873580 001)

Proteinase K (Ambion cat. No. AM2546)

RNase A (Fermantas cat. No. EN0531)

Dynabeads protein G (Invitrogen cat. No. 100.04D)

Dynabeads protein A (Invitrogen cat. No. 100.02D)

Ethanol

Phenol (CAROLO ERBA Cat. no. 108-95-2)

Chloroforms (Prolab cat. No. 22 716.296)

Glycogen (Fermentas cat. No. R0561)

SYBER $^{\circledR}$ Green master mix (Life Technologies)

\section{Equipment}

Sonicator (Bioruptor ${ }^{\circledR}$ UCD-200 from Diagenode)

Vortex

Rotating wheel

Incubator

Freezers $\left(-80\right.$ and $\left.-20^{\circ} \mathrm{C}\right)$

Falcon tubes $(50 \mathrm{ml})$

Eppendorf tubes (1.5 and $2 \mathrm{ml})$

Siliconized eppendorf

Magnet Dynal

\section{Solutions}

Extraction buffer I: $0.4 \mathrm{M}$ sucrose, 1 mini tablet Roche per $50 \mathrm{ml}, 10 \mathrm{mM} \mathrm{MgCl}, 5 \mathrm{mM} 2$ -

MERCAPTOETHANOL, $10 \mathrm{mM}$ Tris- $\mathrm{HCl} \mathrm{pH} 8$

Extraction buffer II: $0.25 \mathrm{M}$ sucrose, $10 \mathrm{mM}$ Tris- $\mathrm{HCl}$

$\mathrm{pH} 8,10 \mathrm{mM} \mathrm{MgCl} 2,1 \%$ triton, 1 mini tablet Roche

diluted in $1 \mathrm{ml}$ (for $10 \mathrm{ml}$ ), $5 \mathrm{mM} 2$ -

MERCAPTOETHANOL

Extraction buffer III: $1.7 \mathrm{M}$ sucrose, 1 minitablet diluted in $1 \mathrm{ml}$ (for $10 \mathrm{ml}$ ), 0.15\% Triton X-100, $2 \mathrm{mM}$ $\mathrm{MgCl} 2,5 \mathrm{mM}$ 2-MERCAPTOETHANOL, $10 \mathrm{mM}$ Tris $\mathrm{HCl} \mathrm{pH} 8$

Nuclei lysis buffer: $50 \mathrm{mM}$ Tris $\mathrm{HCl} \mathrm{pH} 8,10 \mathrm{mM}$ EDTA, 1 mini tablet of protease inhibitors diluted in $1 \mathrm{ml}$ (for $10 \mathrm{ml}$ ), 1\% SDS

ChIP dilution buffer: $1 \%$ triton, $1.2 \mathrm{mM}$ EDTA, $167 \mathrm{mM} \mathrm{NaCl}, 16.7 \mathrm{mM}$ Tris HCl pH8 CRITICAL keep at $4^{\circ} \mathrm{C}$. 
Low salt wash buffer: $150 \mathrm{mM} \mathrm{NaCl}, 0.1 \%$ SDS, 20 mM Tris-HCl pH8, 2 mM EDTA, 1\% Triton X-100 CRITICAL keep at $4^{\circ} \mathrm{C}$.

High salt wash buffer: $500 \mathrm{mM} \mathrm{NaCl}, 0.1 \%$ SDS, $1 \%$ Triton X-100, 20 mM Tris-HCl pH8, 2 mM EDTA CRITICAL keep at $4^{\circ} \mathrm{C}$.

LiCl wash buffer: $0.25 \mathrm{M}$ LiCL, 1\% IGEPAL CA-630, $10 \mathrm{Mm}$ Tris-HCl pH8, 1 mM EDTA, 1\% sodium deoxycholate CRITICAL keep at $4^{\circ} \mathrm{C}$.

TE buffer: $10 \mathrm{Mm}$ Tris-HCl pH8, 1 Mm EDTA CRITICAL keep at $4^{\circ} \mathrm{C}$.

Elution buffer: $1 \%$ SDS, $0.1 \mathrm{M} \mathrm{NaHCO}_{3}$ CRITICAL keep at $4^{\circ} \mathrm{C}$.

CRITICAL: All the buffers should be prepared fresh and when required, the addition of the protease inhibitors, should be done directly before using the buffer.

\section{Protocol}

\section{Harvesting cells and cross-linking}

1. Grow P. tricornutum culture in $400 \mathrm{ml}$ artificial sea water under the standard conditions until cell density reaches around 1 million cells $/ \mathrm{ml}$.

2. Add $11.27 \mathrm{ml}$ of $36.5 \%$ of formaldehyde to the culture to get final $1 \%$ concentration in the whole medium.

3. Stop fixation by adding $2 \mathrm{M}$ glycine (final concentration is $0.125 \mathrm{M}$ ) for $5 \mathrm{~min}$ at room temperature.

4. Wash the cells with PBS solution twice by centrifugation at $4000 \mathrm{rpm}$ for $5 \mathrm{~min}$ at $4^{\circ} \mathrm{C}$.

Comment: Fixed pellet can be stored at $-80^{\circ} \mathrm{C}$ for several months.

\section{Chromatin extraction and sonication}

5. Add approximately $5 \mathrm{ml}$ of Extraction buffer I to $50 \mathrm{ml}$ culture pellet.

6. Leave the falcon tubes on ice for $5 \mathrm{~min}$.

7. Spin the solution at $4000 \mathrm{rpm}$ for $20 \mathrm{~min}$ at $4^{\circ} \mathrm{C}$.

8. Gently remove supernatant and resuspend the pellet in $1 \mathrm{ml}$ of Extraction Buffer II.

9. Spin at $10,000 \mathrm{rpm}$ for $10 \mathrm{~min}$ at $4^{\circ} \mathrm{C}$.

10. Remove supernatant and resuspend pellet in $300 \mu \mathrm{l}$ of Extraction Buffer III.

11. In a clean eppendorf, add $300 \mu \mathrm{l}$ of Extraction Buffer III. Take the $300 \mu$ l solution (resuspended pellet) from last step and carefully layer it on top of the clean $300 \mu \mathrm{l}$ of Extraction Buffer III.

12. Spin at $13,000 \mathrm{rpm}$ for 1 hour at $4^{\circ} \mathrm{C}$.

13. Remove the supernatant and resuspend the chromatin pellet in $300 \mu \mathrm{l}$ (or $200 \mu \mathrm{l}$ if small pellet) of Nuclei Lysis Buffer. Resuspend the pellet by pipetting up and down and vortexing (keep solution cold between vortexing).

14. Sonicate the chromatin solution for 9 cycles 30 seconds $\mathrm{ON}$ and 1 minute OFF for each cycle on full power. Keep $5 \mu \mathrm{l}$ for DNA extraction to check sonication efficiency. CRITICAL Supernatant is usually less than $300 \mu \mathrm{l}$ following sonication due to liquid loss.

15. Check the sonicated chromatin after reverse crosslinking and recovering the DNA on 1\% agarose gel. The DNA fragment should be around $200 \mathrm{bp}$ $1000 \mathrm{bp}$.

Comment: Sonicated chromatin can be frozen at $-80^{\circ} \mathrm{C}$ for 3 months or can be used directly for immunoprecipitation.

\section{Immunoprecipitation and reverse crosslinking}

16. Spin at full speed the chromatin solution for 5 minutes at 4 degrees to pellet debris. Remove supernatant to a new tube. CRITICAL It is important to remove $20 \mu \mathrm{l}$ for Total DNA Control for INPUT.

17. Measure out the remaining volume of sonicated chromatin and bring volume up to $3 \mathrm{ml}$ with ChIP Dilution Buffer. The point here is to dilute the 1\% SDS to $0.1 \%$ SDS with ChIP dilution buffer.

18. Split the chromatin solution into 3 tubes $(1 \mathrm{ml}$ each).

Tube 1. With DNA A beads labeled H3K4me Tube 2. With DNA A beads labeled H3K9me ${ }^{2}$ Tube 3. With DNA A beads labeled No Antibody (mock)

19. For each IP, mix $45 \mu \mathrm{l}$ beads A and $45 \mu \mathrm{l}$ DNA beads $\mathrm{G}$ in siliconized tubes. Wash DNA beads twice with ChIP Dilution buffer and resuspend beads in $90 \mu \mathrm{l}$ Chip dilution buffer. Split the $90 \mu \mathrm{l}$ resuspended beads into 30 and $60 \mu \mathrm{l}$ volumes.

20. Add $5 \mu \mathrm{l}$ of your antibody to the siliconized eppendorf tube that contains mixed $60 \mu \mathrm{l}$ beads for Ig capturing. Add the diluted chromatin solutions into the tubes that contain $30 \mu \mathrm{l}$ mixed beads for preclearing. Leave tubes with gentle rotation at $4^{\circ} \mathrm{C}$ for 2 hours.

Comment: Using precleared chromatin and siliconized eppendorf tubes can significantly decrease negative control (mock) noise background.

21. Wash the beads-Ig complexes once by $1 \mathrm{ml} \mathrm{ChIP}$ dilution buffer and resuspend in $60 \mu \mathrm{l}$ ChIP dilution buffer. Transfer the precleared chromatin into the 
beads-Ig complexes. Leave tubes with gentle rotation at $4^{\circ} \mathrm{C}$ overnight.

22. Wash the DNA beads-Ig-antigen complexes 4 times using Low Salt Wash Buffer, High Salt Wash Buffer, $\mathrm{LiCl}$ Wash Buffer and TE Buffer in sequence. Use $1 \mathrm{ml}$ of each buffer per wash and wash twice per sample. One wash is quick without agitation and the other one is at $4^{\circ} \mathrm{C}$ with gentle rotation for 5 min.

Comment: Put all the wash solutions on ice prior to immune complex collection.

23. Elute immune complexes by adding $250 \mu \mathrm{l}$ of Elution Buffer to the washed beads. Vortex briefly for mixing and incubate at $65^{\circ} \mathrm{C}$ for $15 \mathrm{~min}$ (mix tubes during incubation). Put tubes on the magnet Dynal and carefully transfer the eluate to another eppendorf tube (not siliconized tube) and repeat elution once again. Combine them to obtain final $500 \mu \mathrm{l}$ of elute.

25. Add $20 \mu \mathrm{l} 5 \mathrm{M} \mathrm{NaCl}$ to the eluate and reverse crosslink at $65^{\circ} \mathrm{C}$ overnight.

Comment: Do not forget to get your total DNA out of the freezer and reverse cross-link with other samples (Add $500 \mu \mathrm{l}$ of Elution buffer $+20 \mu \mathrm{l} 5 \mathrm{M} \mathrm{NaCl}$ ).

\section{DNA recovery}

26. Add $10 \mu \mathrm{l}$ of $0.5 \mathrm{M}$ EDTA, $20 \mu \mathrm{l}$ Tris-HCl $1 \mathrm{M}$ (pH 6.5), $2 \mu \mathrm{l}$ of $10 \mathrm{mg} / \mathrm{ml}$ proteinase $\mathrm{K}$, and $1 \mu \mathrm{l}$ of $10 \mathrm{mg} / \mathrm{ml} \mathrm{RNase}$ to the eluate and incubate for one hour at $45^{\circ} \mathrm{C}$.

27. Recover DNA by phenol and chloroform (phenol; phenol/chloroform 1:1; chloroform) extraction (equal volume) and precipitate DNA with $\mathrm{EtOH}$ (2 vol 1/2) and 1/10 vol NaAc (3 M pH 5.3). Add $2 \mu \mathrm{l}$ glycogen $(20 \mathrm{mg} / \mathrm{ml})$ to ethanol precipitation step. Incubate at $-80^{\circ} \mathrm{C}$ for $15 \mathrm{~min}$ or 2 hours at $-20^{\circ} \mathrm{C}$.

28. Centrifuge at $4^{\circ} \mathrm{C}$ at $13,000 \mathrm{rpm}$ for $30 \mathrm{~min}$ and wash pellets with $400 \mu \mathrm{l} 70 \%$ ethanol. Dry the pellet at room temperature.

29. Resuspend the pellet in $50 \mu \mathrm{l}$ of distilled water or $30 \mu$ to concentrate DNA.

\section{Quantitative PCR}

For both diatoms, specific primers were designed for two genes and a set of TEs (Table 1). The input DNA pulled out from ChIP was diluted 10 times before q-PCR. Quantitative PCR was performed using a Roche LightCycler ${ }^{\circledR}$ 480 machine on $1 \mu \mathrm{l}$ of IP, input and mock DNA which were mixed to $5 \mu \mathrm{l} \mathrm{LightCycler}{ }^{\circledR}$ DNA Master SYBR Green I 2X, $3 \mu \mathrm{l}$ forward/reverse primers $1 \mu \mathrm{M}$, and $1 \mu \mathrm{L}$ $\mathrm{H} 2 \mathrm{O}$. The PCR program was performed as follows:
Table 1 Primer sequences used for QPCR analysis

\begin{tabular}{|c|c|}
\hline Primer name & Sequence \\
\hline Tp H4 Promoter fw & AGCCTGATGGAGAGAGTGGA \\
\hline Tp H4 Promoter rev & TACATCCAGGACCTCCGTTC \\
\hline Tp H4 body fw & TCGTAGAAAACGGTCCCATC \\
\hline Tp H4 body rev & CCTCCACTTGGAAGAAGCAG \\
\hline Tp Phyto promoter fw & CGATGTTGGTTGAGTGTTGG \\
\hline Tp Phyto promoter rev & GCGATGTGCTCTITITGACA \\
\hline Tp Phyto body fwd & TITGGATTCCGTGAGAAAGG \\
\hline Tp Phyto body rev & GTCTCGTGCACTCATCTCCA \\
\hline Tp EU432485 fw & CCAGAGCTCGACAAACATGA \\
\hline Tp EU432485 rev & TCGTITCCCTACGTGGAAC \\
\hline Tp EU432490 fw & AGGAACTCGGAGACAAAGCA \\
\hline Tp EU432490 rev & ATGTGCCCTCTTCAACAACC \\
\hline Tp EU432492 fw & GCTCTGTCGTCGGAAAACTC \\
\hline Tp EU432492 rev & AGGACAGCCTGCGTAGAAAA \\
\hline Tp EU432500 fw & TGATGCAACAGGACGAAGAG \\
\hline Tp EU432500 rev & GCATTGTTGGCCTTGTACCT \\
\hline Pt H4 promoter fw & GTTGGTCGTCCATCGTTAGC \\
\hline Pt H4 promoter rev & CCGTGGACGTTCTTGGTAGT \\
\hline Pt H4 body fw & AATTACCAAGCCCGCTATCC \\
\hline Pt H4 body rev & GTTCTGTGAAACGGCAGGT \\
\hline Pt PHY promoter fw & CTTGCCATGTCTTTGCAGTG \\
\hline Pt PHY promoter rev & GTCAACACGCAATCAAGCAC \\
\hline Pt PHY body1 fw & CAGCGACGGAAATGGACTAC \\
\hline Pt PHY body 1 rev & TTAGCAAGCAAGTGCGTCAG \\
\hline Pt BKB4022 fw & CGAAGCTACTATGCCGGAAG \\
\hline Pt BKB4022 rev & AAGGACACGAGAGTCGAGGA \\
\hline PTC30 fw & CGGACTTCACCGAAGACAAT \\
\hline PTC30 rev & GAATGGCTITGGCATCATCT \\
\hline PTC66 fw & AGCGATGGAACATTGGTTTATC \\
\hline PTC66 rev & AACGTATCGTGAGCCTGACC \\
\hline PTC25 fw & GCCTACCCCATGAAAACTGA \\
\hline PTC25 rev & AGGCTCACTCTGCCACTGAT \\
\hline SCF FW & CAGCCTGAGGCGAAAGATAC \\
\hline SCF rev & TAGTTCTGACATGCGCCAAG \\
\hline
\end{tabular}

10 min at $95^{\circ} \mathrm{C}$; 45 cycles of $95^{\circ} \mathrm{C}$ for 15 seconds and $60^{\circ} \mathrm{C}$ for $1 \mathrm{~min}$.

\section{Data analysis}

The $\mathrm{Ct}$ value (number of cycles required for the fluorescent signal to cross the threshold) is recorded in the experimental report after analysis by Roche LightCycler ${ }^{\circledR}$ 480 software. The Ct values of the duplicates should show minimal variability, indicating that samples were properly handled (ideally, it should be below 0.2). Ct values were used for performing the calculation which consists on 
evaluating the fold difference between experimental sample and normalized input.

$\Delta \mathrm{Ct}$ (normalized to the input samples) value for each sample. $\Delta \mathrm{Ct}$ [normalized ChIP] $=(\mathrm{Ct}$ [ChIP] $-(\mathrm{Ct}$ [Input $]-$ Log2 (Input Dilution Factor).

Where Input Dilution Factor $=$ (fraction of the input chromatin saved) ${ }^{-1} \times$ Input dilution factor before q PCR. Here the fraction of Input chromatin saved is $20 \mu \mathrm{l}$ and the fraction for each IP is $90 \mu \mathrm{l}$. The IP fraction is 4.5 times the input fraction. For QPCR runs Input was diluted 10 times which makes the final dilution factor of the Input fraction (Input Dilution Factor) $=4.5 \times 10=45$. Then the equation above is as follows: $\Delta \mathrm{Ct}$ [normalized ChIP] $=(\mathrm{Ct}[\mathrm{ChIP}]-$ (Ct [Input] - Log2 (45). Finally, the percentage (Input \%) value for each sample is calculated as follows: Input \%= 100/2 $\Delta$ Ct [normalized ChIP]. The "Input \%" value represents the enrichment of certain histone modification on specific region.

\section{Peptide competition assay and western blot}

The antibody was pre-incubated with the peptide prior to use in immunoblotting assays. Different amounts (depends on different peptides and antibody) of peptides were added to a $10 \mathrm{ml} \mathrm{BSA}$ solution containing antibody and incubated under gentle agitation for $4 \mathrm{~h}$ at room temperature and an additional 1 hour at $4^{\circ} \mathrm{C}$ before the immunoblotting assays. Calibration curve were performed for each antibody to determin the amount of antibody to use (data not shown). The antibodies and peptides used in this work include H3K4me2 (Millipore Ref: 07-030), H3K9me2 (Millipore, Ref: 17-681), H3K4me1 peptide (Abcam Ref: ab1340), H3K4me2 peptide (Abcam Ref: ab7768), H3K4me3 peptide (Abcam Ref: ab1342), H3K9me1 peptide (Millipore, Ref: 12-569), H3K9me2 peptide (Millipore, Ref: 12-430), H3K9me3 peptide (Millipore, Ref: 12-568). The references of H3K9me2 antibodies that were discarded because of the lack of specificity are Millipore Ref: 17-648 and Millipore ref: 05-1249. Different concentrations of antibody and peptide concentration were compared. The nuclear enriched protein used for immunoblotting was extracted following the chromatin extraction protocol with minor modifications: the culture was not fixed by formaldehyde and sonication was not needed.

\section{Results and discussion}

\section{Chromatin extraction and processing}

ChIP is a very powerful technique for revealing association of specific DNA regions with proteins of interest. However, it is not a trivial technique, and highly specific antibodies against the protein of interest or a particular histone modification are required. Furthermore, false-negative signals may originate from inefficient antibody binding, and the beads used in ChIP can bind non-specific sites and cause background noise in negative controls. The starting materials for immunoprecipitation are also critical in terms of number of cells in a given volume, and sample dilution can effectively decrease background noise. To avoid saturation of antibody in ChIP assays, calibration curves should be built before precipitation with the antibody to determine the optimal amount of antibody to use.

The protocol described herein (Figure 1) has taken into consideration these issues as well as the particularities of diatoms. Diatoms have the unique ability to precipitate soluble silicic acid into a finely patterned cell wall built from amorphous silica, and they also possess photosynthetic chloroplasts. Chromatin extraction buffers modified from Arabidopsis ChIP protocols were used for P. tricornutum and T. pseudonana which have plant features, such as chloroplasts and a cell wall. It is important in this protocol to use artificial sea water instead of natural sea water in order to control the different components of the medium such as silica. Extraction of chromatin from diatom species can be difficult because of the silica based rigid cell wall [11], which can interfere with chromatin extraction because it binds DNA. In this study, we have chosen species that have different requirements for silicon. P. tricornutum has a facultative requirement for silicic acid, whereas T. pseudonana needs a silicon source to grow. A growth medium without silicic acid was used for $P$. tricornutum while $T$. pseudonana grew in medium containing a relatively high concentration of silica $(\sim 88 \mu \mathrm{M})$ reflecting the amount found in natural environment.

To preserve cell integrity, diatom cells were fixed in the growth medium prior to any handling. Formaldehyde was used for cross linking. Cross linking is a time dependent procedure and our trials have established 10 minutes as an optimal time for both P. tricornutum and T. pseudonana. Excessive cross linking might reduce antigen accessibility and sonication efficiency. For a different diatom species, we recommend 5 minutes for a start, proceed with sonication, reverse cross link and run a gel to see how much DNA is recovered and whether the size is optimal. If not, we recommend trying longer or shorter times for cross linking.

Sonication time was determined after trying three different times, 7 cycles of 25 seconds $\mathrm{ON}$ and 1 minute OFF, 9 and 12 cycles with 30 seconds $\mathrm{ON}$ and 1 minute OFF. Nine cycles gave the best range of DNA sizes which is between 220 and 1000 bp with a maximum of DNA fragments at 500 bp (Figure 2). Different dilutions of $200 \mathrm{ml}$ sample containing 5 million cells per $\mathrm{ml}$ were used for sonication as high cell density can interfere with the efficiency of sonication. Four times dilution gave the best range of fragment sizes (Figure 2).

\section{Peptide competition assay}

The nuclear-enriched protein used for immunoblotting was extracted following a chromatin extraction protocol with minor modifications (see Methods section). 


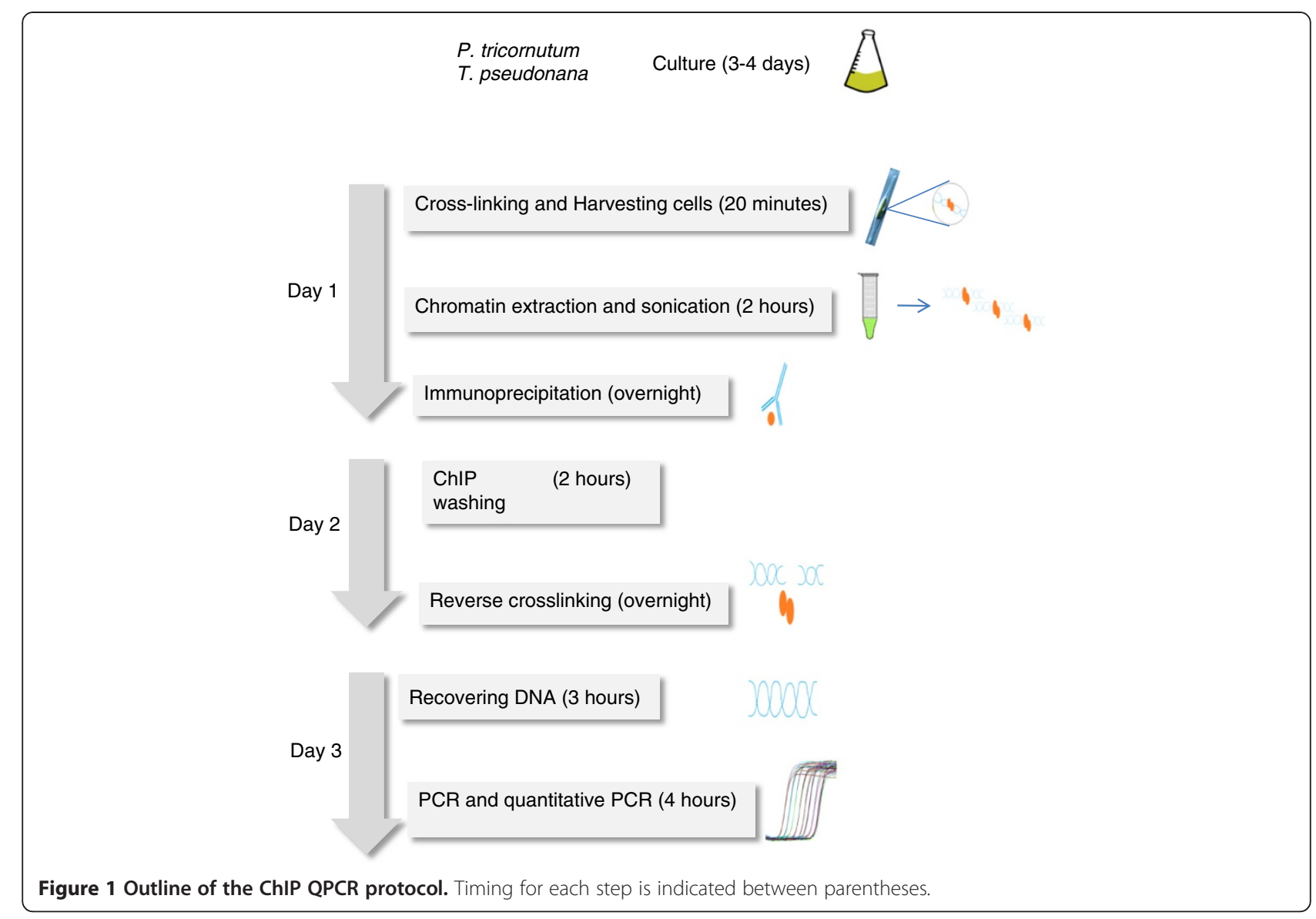

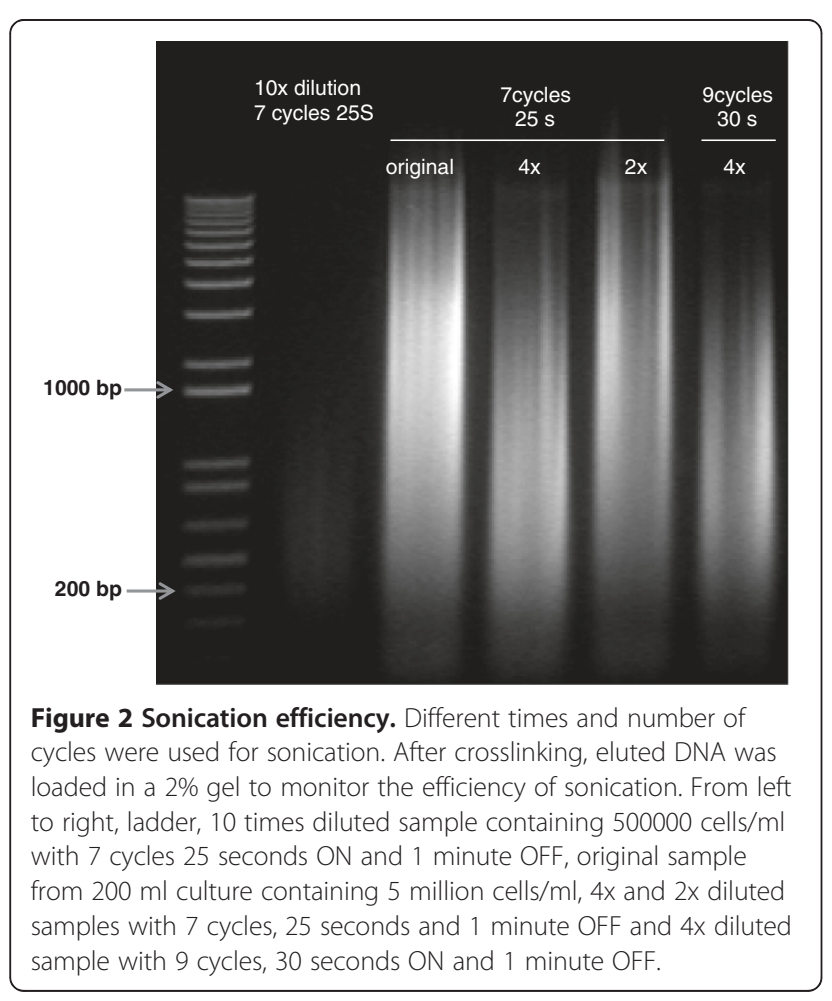

Antibodies for two histone marks H3K4me2 and H3K9me2 were used for validation of the ChIP protocol. A peptide competition assay was performed to confirm the specific band reactivity of the antibodies. This is an important issue especially for genome wide studies as unspecific antibody binding will lead to non-specific signals increasing background noise and the occurrence of false positives. Both antibodies were pre-incubated with three different concentrations of the corresponding peptides (see Methods section) prior to immunobloting. For the H3K4me2 histone mark, the peptide competition assay did not detect the presence of a band for peptide H3K4me2 while a band was seen for the two other peptides, indicating the absence of competition with the other modifications of lysine 4 (Figure 3A). Three different H3K9me2 antibodies from Millipore were tested in this assay (see methods section for references). Two of them were discarded because of a lack of specificity while the third one gave better results in terms of specificity and noise (Figure 3B).

\section{H3K4me2 is enriched in genes in $P$. tricornutum and $T$.} pseudonana

Quantitative real time transcriptase polymerase chain reaction (Q-PCR) coupled with the ChIP protocol 


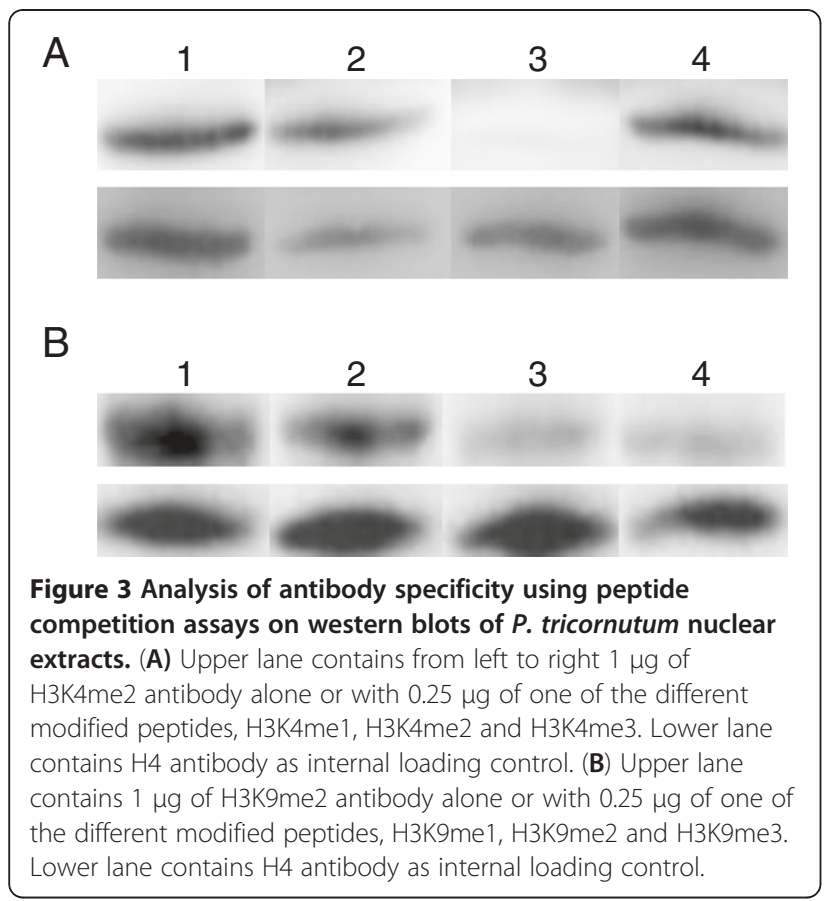

described herein was used to investigate the enrichment of H3K4 and H3K9 dimethylation on two genes, histone $\mathrm{H} 4$ and diatom phytochrome (Dph), and four transposable elements (TEs) in P. tricornutum and T. pseudonana. A clear enrichment of genes in H3K4me2 shown by a set of primers spanning promoter and gene body was demonstrated by Q-PCR (Figure 4A). Both histone $\mathrm{H} 4$ and Dph show significant differences in the enrichment in H3K4me2 between immunoprecipitated sample and mock which is the no antibody control. However, no significant differences were observed for the five TEs chosen in this study. Likewise, in T. pseudonana, the Dph and histone H4 show enrichment in H3K4me2 in both promoter and gene body, whereas the four chosen TEs (C12, C4, C19 and G1) show no enrichment in H3K4me2 (Figure 4B). Additional genes and TEs were tested and showed similar results (data not shown). Altogether, our data show a conservation of H3K4me2 location between the two diatom species and multicellular organisms, because genome wide studies in plants and mammals have indeed shown the presence of H3K4me2 on genes [12-14].

\section{H3K9me2 shows a different enrichment profile in $P$. tricornutum and T. pseudonana}

ChIP analysis of H3K9me2 in P. tricornutum revealed that TEs contain a significant enrichment for this mark. We particularly focused on two previously characterized diatom-specific copia-like retrotransposable elements known as Blackbeard (Bkb) and Surcouf (Scf) [15] Bkb was particularly enriched in H3K9me2 while $S c f$ was the
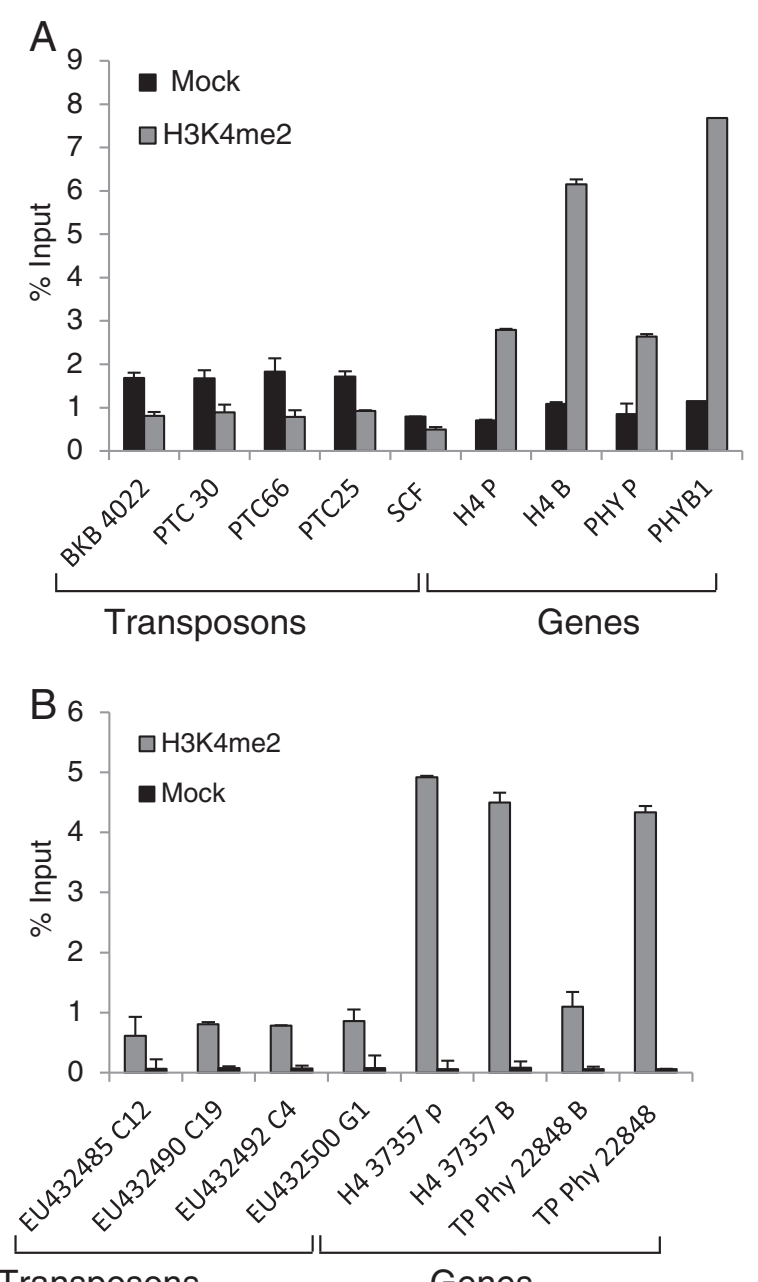

Transposons

Genes

Figure $4 \mathrm{H} 3 \mathrm{~K} 4 \mathrm{me} 2$ histone modification on different regions of genes and TEs in P. tricornutum (A) and T. pseudonana (B). \% IP indicates the enrichment. $\mathrm{H} 4 \mathrm{P}$ : promoter region of $\mathrm{H} 4$ histone gene. $\mathrm{H} 4 \mathrm{~B}$ : body region of $\mathrm{H} 4$ histone gene. PHY P: promoter region of Dph gene. PHY B: body region of Dph.

least enriched. Intermediate levels were observed among the remaining TEs (Figure 5A). On the other hand, the two protein-coding genes histone $\mathrm{H} 4$ and $\mathrm{Dph}$ were clearly depleted of H3K9me2 in both promoter and gene body regions (Figure 5A). Both genes were shown by us and others to be transcriptionally active ([5], unpublished results). It was previously shown that $B k b$ and $S c f$ are also transcriptionally inactive in normal growth conditions [15]. This is consistent with the primary function of H3K9me2 in repressing TEs in order to maintain genome stability. In P. tricornutum, the ChIP assay shows that repressed TEs are marked by H3K9me2 while active genes are depleted in this mark which is similar to what has been observed in plants and mammals $[16,17]$.

In T. pseudonana, a similar pattern of enrichment of TEs by H3K9me2 was observed (Figure 5B). The four 


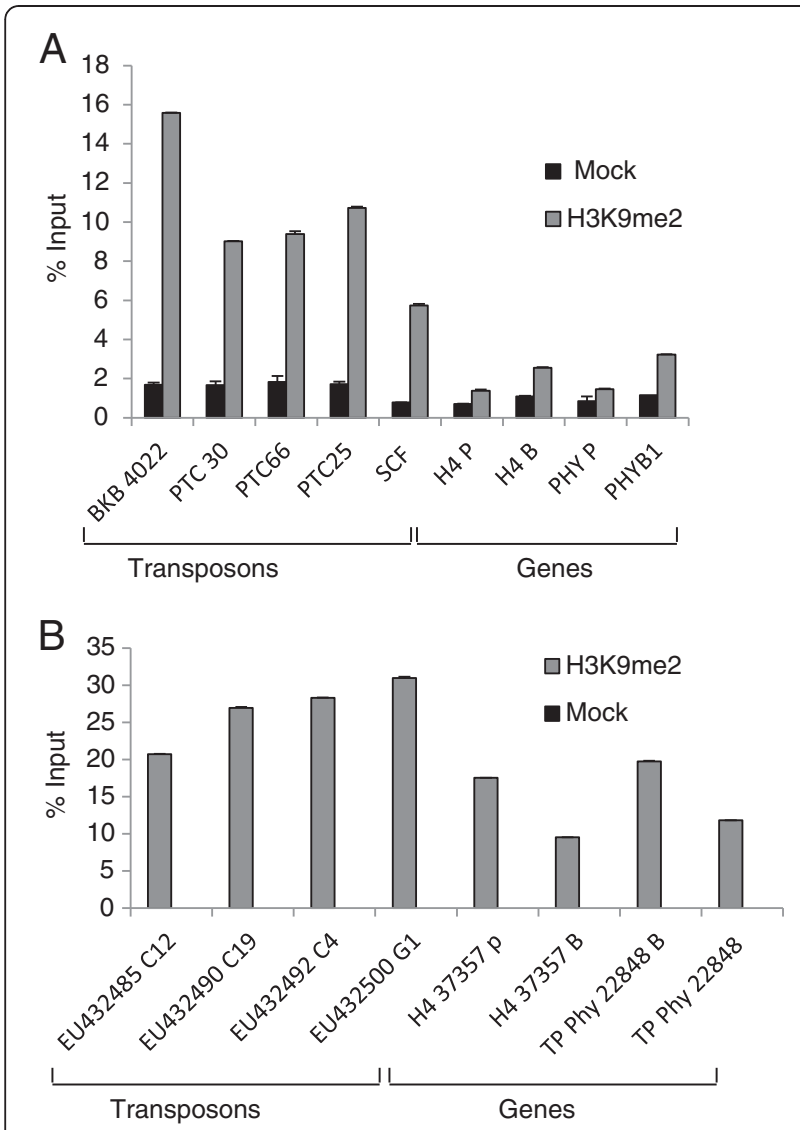

Figure $5 \mathrm{H} 3 \mathrm{~K} 9 \mathrm{me} 2$ histone modification on different regions of genes and TEs in P. tricornutum (A) and T. pseudonana (B). \% IP indicates the enrichment. $\mathrm{H} 4 \mathrm{P}$ : promoter region of $\mathrm{H} 4$ histone gene. $\mathrm{H} 4 \mathrm{~B}$ : body region of $\mathrm{H} 4$ histone gene. PHY P: promoter region of Dph gene. PHY B: body region of Dph. Mock values are indistinguishable from $0 \%$ in T. pseudonana.

tested TEs were highly enriched for H3K9me2, indicating a conserved profile for this mark among both diatoms. Surprisingly, some genes also showed a significant enrichment for $\mathrm{H} 3 \mathrm{~K} 9 \mathrm{me} 2$, particularly at promoter regions (Figure 5B). This unusual association of $\mathrm{H} 3 \mathrm{~K} 9 \mathrm{me} 2$ with active genes can be due to an intrinsic feature of the centric diatom $T$. pseudonana which is believed to have diverged from its distantly related pennate diatom $P$. tricornutum 90 million years ago. Comparative genomics and analysis of molecular divergence has shown indeed that both genomes are as different as those of mammals and fish [4]. Furthermore, combinatorial patterns of antagonistic chromatin marks are known to occur [18-21]. In Drosophila S2 cells, clusters of transcriptionally active genes were reported to be enriched in H3K9me2 [22]. Similarly, differentiated mouse ES cells were reported to contain large domains of H3K9me2 [23]. A hypothesis is that combinatorial chromatin marks can poise genes for transcription, creating more flexible chromatin states ready to adjust for subtle changes in the microenvironment of regulated genes [22,24]. The presence of chromatin marks known to be silent on euchromatin regions or active genes is intriguing and future analysis will be particularly important for elucidating this question.

\section{Conclusions}

The ChIP protocol described herein provides reproducible results with two different diatom species grown in different media. The quality of the procedure monitored by the no antibody control is high as no or insignificant background noise was observed. This protocol is also rapid, and can be completed within 3 days. The quantity and quality of eluted DNA from immunoprecipitation are also satisfactory. Using the described ChIP method combined with real time quantitative PCR, we have demonstrated the existence in diatoms of two types of histone modifications, H3K4me2 and H3K9me2. The H3K4me2 mark is associated with transcriptionally active genes in $P$. tricornutum and $T$. pseudonana. This result is consistent with the distribution of H3K4me2 in plants and mammals. H3K9me2 binds TEs whereas no association with genes was detected in $P$. tricornutum. In T. pseudonana, H3K9me2 also correlated significantly with TEs, although it also appears to bind protein-coding genes. This is different from the distribution pattern of H3K9me2 in P. tricornutum. The differences of H3K9me2 distribution pattern between $P$. tricornutum and T. pseudonana may be inherent to the genetic and/or epigenetic background of the two species which belong to pennate and centric diatoms, respectively. Gene enrichment with H3K9me2 could be further confirmed by a genome wide study of H3K9me2 distribution. Our results show that our experimental and data analysis approach are indeed highly sensitive to detect differences between the two species if they do occur. The ChIP protocol we describe can be combined with microarray or massively parallel sequencing for further genome-wide studies. This protocol has been indeed successfully combined with Illumina sequencing for studies of global histone modifications in $P$. tricornutum (unpublished results). Furthermore, our ChIP assay can likely be easily adapted to other eukaryotic phytoplankton species for in vivo protein DNA interaction studies.

\section{Acknowledgements}

Funding for this work was provided by the Agence Nationale de Recherche (France) and a European Research Council Advanced Grant award to CB.

Received: 24 October 2012 Accepted: 5 December 2012

Published: 7 December 2012

\section{References}

1. Round FE, Crawford RM, Mann DG: The diatoms: biology and morphology of the genera. London, UK: Cambridge University Press; 1990.

2. Nelson DM, Trequer P, Brzezinski MA, Leynaert A, Queguiner B: Production and dissolution of biogenic silica in the ocean - revised global estimates, comparison with regional data and relationship to biogenic sedimentation. Global Biogeochem Cycles 1995, 9:359-372. 
3. Armbrust EV, Berges JA, Bowler C, Green BR, Martinez D, Putnam NH, Zhou $\mathrm{S}$, Allen AE, Apt KE, Bechner $M$, et al: The genome of the diatom Thalassiosira pseudonana: ecology, evolution, and metabolism. Science 2004, 306:79-86.

4. Bowler C, Allen AE, Badger JH, Grimwood J, Jabbari K, Kuo A, Maheswari U, Martens C, Maumus F, Otillar RP, et al: The Phaeodactylum genome reveals the evolutionary history of diatom genomes. Nature 2008, 456:239-244.

5. Siaut M, Heijde M, Mangogna M, Montsant A, Coesel S, Allen A, Manfredonia A, Falciatore A, Bowler C: Molecular toolbox for studying diatom biology in Phaeodactylum tricornutum. Gene 2007, 406:23-35.

6. De Riso V, Raniello R, Maumus F, Rogato A, Bowler C, Falciatore A: Gene silencing in the marine diatom Phaeodactylum tricornutum. Nucleic Acids Res 2009, 37:e96.

7. Gendrel AV, Lippman Z, Martienssen R, Colot V: Profiling histone modification patterns in plants using genomic tiling microarrays. Nature methods 2005, 2:213-218.

8. Grably M, Engelberg D: A detailed protocol for chromatin immunoprecipitation in the yeast Saccharomyces cerevisiae. Methods mol biol 2010, 638:211-224.

9. Saleh A, Alvarez-Venegas R, Avramova Z: An efficient chromatin immunoprecipitation (ChIP) protocol for studying histone modifications in Arabidopsis plants. Nat Protoc 2008, 3:1018-1025.

10. Nelson JD, Denisenko O, Bomsztyk K: Protocol for the fast chromatin immunoprecipitation (ChIP) method. Nat Protoc 2006, 1:179-185.

11. Kim BH, Ramanan R, Cho DH, Choi GG, La HJ, Ahn CY, Oh HM, Kim HS: Simple, rapid and cost-effective method for high quality nucleic acids extraction from different strains of Botryococcus braunii. PLoS One 2012 7:e37770.

12. Liu CL, Kaplan T, Kim M, Buratowski S, Schreiber SL, Friedman N, Rando OJ: Single-nucleosome mapping of histone modifications in S. cerevisiae. PLoS biol 2005, 3:e328.

13. Mikkelsen TS, Ku M, Jaffe DB, Issac B, Lieberman E, Giannoukos G, Alvarez P, Brockman W, Kim TK, Koche RP, et al: Genome-wide maps of chromatin state in pluripotent and lineage-committed cells. Nature 2007, 448:553-560.

14. Zhang $X$, Bernatavichute $Y$, Cokus S, Pellegrini M, Jacobsen SE: Genome-wide analysis of mono-, di- and trimethylation of histone $\mathrm{H} 3$ lysine 4 in Arabidopsis thaliana. Genome Biol 2009, 10:R62.

15. Maumus F, Allen AE, Mhiri $C$, Hu H, Jabbari K, Vardi A, Grandbastien MA, Bowler C: Potential impact of stress activated retrotransposons on genome evolution in a marine diatom. BMC Genomics 2009, 10:624.

16. Zhou J, Wang X, He K, Charron JB, Elling AA, Deng XW: Genome-wide profiling of histone $\mathrm{H} 3$ lysine 9 acetylation and dimethylation in Arabidopsis reveals correlation between multiple histone marks and gene expression. Plant Mol Biol 2010, 72:585-595.

17. Tachibana M, Sugimoto K, Nozaki M, Ueda J, Ohta T, Ohki M, Fukuda M, Takeda N, Niida H, Kato H, Shinkai Y: G9a histone methyltransferase plays a dominant role in euchromatic histone $\mathrm{H} 3$ lysine 9 methylation and is essential for early embryogenesis. Genes Dev 2002, 16:1779-1791.

18. Bapat SA, Jin V, Berry N, Balch C, Sharma N, Kurrey N, Zhang S, Fang F, Lan X, Li M, et al: Multivalent epigenetic marks confer microenvironmentresponsive epigenetic plasticity to ovarian cancer cells. Epigenetics: off j DNA Methylation Soc 2010, 5:716-729.

19. Bernstein BE, Mikkelsen TS, Xie X, Kamal M, Huebert DJ, Cuff J, Fry B, Meissner A, Wernig M, Plath K, et al: A bivalent chromatin structure marks key developmental genes in embryonic stem cells. Cell 2006, 125:315-326.

20. Roudier F, Ahmed I, Berard C, Sarazin A, Mary-Huard T, Cortijo S, Bouyer D, Caillieux E, Duvernois-Berthet E, Al-Shikhley L, et al: Integrative epigenomic mapping defines four main chromatin states in Arabidopsis. EMBO J 2011, 30:1928-1938.

21. Weishaupt $H$, Sigvardsson M, Attema JL: Epigenetic chromatin states uniquely define the developmental plasticity of murine hematopoietic stem cells. Blood 2010, 115:247-256.

22. Riddle NC, Minoda A, Kharchenko PV, Alekseyenko AA, Schwartz YB, Tolstorukov MY, Gorchakov AA, Jaffe JD, Kennedy C, Linder-Basso D, et al:
Plasticity in patterns of histone modifications and chromosomal proteins in Drosophila heterochromatin. Genome Res 2011, 21:147-163.

23. Wen B, Wu H, Shinkai Y, Irizarry RA, Feinberg AP: Large histone H3 lysine 9 dimethylated chromatin blocks distinguish differentiated from embryonic stem cells. Nat Genet 2009, 41:246-250.

24. Lanzuolo C, Lo Sardo F, Orlando V: Concerted epigenetic signatures inheritance at PcG targets through replication. Cell cycle 2012, 11:1300.

doi:10.1186/1746-4811-8-48

Cite this article as: Lin et al:: Protocol: Chromatin immunoprecipitation (ChIP) methodology to investigate histone modifications in two model diatom species. Plant Methods 2012 8:48.

\section{Submit your next manuscript to BioMed Central and take full advantage of:}

- Convenient online submission

- Thorough peer review

- No space constraints or color figure charges

- Immediate publication on acceptance

- Inclusion in PubMed, CAS, Scopus and Google Scholar

- Research which is freely available for redistribution

Submit your manuscript at www.biomedcentral.com/submit

C BioMed Central 